\title{
A Novel Form of Hereditary Myeloperoxidase Deficiency Linked to Endoplasmic Reticulum/Proteasome Degradation
}

\author{
Frank R. DeLeo, Melissa Goedken, Sally J. McCormick, and William M. Nauseef \\ Department of Medicine and the Inflammation Program, Veterans Administration Medical Center and University of Iowa, Iowa City, \\ Iowa 52242
}

\begin{abstract}
Myeloperoxidase (MPO) deficiency is a common inherited disorder linked to increased susceptibility to infection and malignancy. We identified a novel missense mutation in the MPO gene at codon 173 whereby tyrosine is replaced with cysteine (Y173C) that is associated with MPO deficiency and assessed its impact on MPO processing and targeting in transfectants expressing normal or mutant proteins. Although the precursor synthesized by cells expressing the Y173C mutation $\left(\mathrm{MPO}_{\mathrm{Y} 173 \mathrm{C}}\right)$ was glycosylated, associated with the molecular chaperones calreticulin and calnexin, and acquired heme, it was neither proteolytically processed to mature MPO subunits nor secreted. After prolonged association with calreticulin and calnexin in the endoplasmic reticulum, $\mathrm{MPO}_{\mathrm{Y} 173 \mathrm{C}}$ was degraded. Furthermore, the $20 \mathrm{~S}$ proteasome inhibitor $N$-acetyl-L-leucinyl-L-leucinyl-L-norleucinyl inhibited its degradation, suggesting that the proteasome mediates proteolysis of $\mathrm{MPO}_{\mathrm{Y} 173 \mathrm{C}}$ and, thus, participates in quality control in this novel form of hereditary MPO deficiency. (J. Clin. Invest. 1998. 101:2900-2909.) Key words: myeloperoxidase - polymorphonuclear leukocyte • endoplasmic reticulum $\bullet$ proteasome $\bullet$ molecular chaperone
\end{abstract}

\section{Introduction}

Myeloperoxidase (MPO) $)^{1}$ (donor: $\mathrm{H}_{2} \mathrm{O}_{2}$ oxidoreductase, EC 1.11.1.7) is a $150-\mathrm{kD}$ hemoprotein stored exclusively in the azurophilic granules of monocytes and neutrophils (PMNs). During PMN activation, MPO is released into the phagosome

Address correspondence to Dr. William M. Nauseef, SW54 GH, Department of Medicine, University of Iowa, 200 Hawkins Drive, Iowa City, IA 52242. Phone: 319-356-1739; FAX: 319-356-4600; E-mail: william-nauseef@uiowa.edu

Received for publication 23 December 1997 and accepted in revised form 14 April 1998.

1. Abbreviations used in this paper: ALA, aminolevulinic acid; ALLM, $N$-acetyl-L-leucinal-L-leucinal-L-methional; ALLN, $N$-acetylL-leucinyl-L-leucinyl-L-norleucinyl; CFTR, cystic fibrosis transmembrane conductance regulator; CLN, calnexin; CRT, calreticulin; endo $\mathrm{H}$, endoglycosidase $\mathrm{H}$; ER, endoplasmic reticulum; MPO, myeloperoxidase; $\mathrm{MPO}_{\mathrm{Y} 173 \mathrm{C}}$, the precursor synthesized by cells expressing Y173C; $N$-GF, $N$-glycanase F; TBS, Tris-buffered saline; TM, tunicamycin; WT-MPO, K562 cells transfected with cDNA encoding normal MPO; Y173C, missense mutation in MPO gene at codon 173 whereby tyrosine is replaced by cysteine.

J. Clin. Invest.

(C) The American Society for Clinical Investigation, Inc. 0021-9738/98/06/2900/10 \$2.00

Volume 101, Number 12, June 1998, 2900-2909

http://www.jci.org or extracellular space where, in the presence of hydrogen peroxide $\left(\mathrm{H}_{2} \mathrm{O}_{2}\right)$ generated by the PMN NADPH-dependent oxidase and chloride ions, hypochlorous acid and other highly toxic species are generated (1-5).

MPO is synthesized only during the promyelocytic stage of myeloid cell development and the $75-80-\mathrm{kD}$ primary translation product is modified in the endoplasmic reticulum (ER) by cotranslational N-linked glycosylation followed by deglucosylation to generate the $90-\mathrm{kD}$ apoproMPO (6-8). During its maturation and processing, the $90-\mathrm{kD}$ precursor MPO interacts transiently with the molecular chaperones calreticulin (CRT) (9) and calnexin (CLN) (10). After heme insertion, proMPO is processed further in a post-ER, pregranule compartment resulting in mature 59- and $13.5-\mathrm{kD}$ subunits that are linked by a disulfide bond to form a single heterodimer (6-8). Two heterodimers are linked by an additional disulfide bond to form the mature molecule that is stored in azurophilic granules (6-8). In addition to the enzyme destined for the azurophilic granule, a significant fraction of normal proMPO enters the secretory pathway where it is modified in the Golgi complex en route to extracellular release $(11,12)$.

The MPO- $\mathrm{H}_{2} \mathrm{O}_{2}$-halide system represents the most efficient oxygen-dependent microbicidal mechanism in PMNs (1). PMNs that lack MPO or in which MPO activity is inhibited with sodium azide have retarded bactericidal activity and absent candidacidal function in vitro $(7,13)$. In addition, MPOdeficient subjects have been reported to have increased susceptibility to infection and malignancy (7). We previously identified a missense mutation in exon 10 of the MPO gene as the molecular basis for one form of inherited MPO deficiency. In the mutant protein, tryptophan replaces arginine at codon 569 (11) and this substitution results in defective processing of the protein such that heme is not inserted into the apoenzyme. As a result, proMPO is not made and the mature subunits of MPO are not generated (11). However, this mutation does not account for all cases of MPO deficiency (14) and the precise mechanism for the arrest in maturation has not been identified.

In this report, we describe a genotypically distinct form of MPO deficiency characterized by a single missense mutation predicting an amino acid substitution of cysteine for tyrosine at codon 173 (Y173C) and assess the impact of this mutation on the biosynthesis and maturation of MPO. The results indicate that CRT and CLN function to retain misfolded mutant MPO precursor in the ER for eventual degradation by the cytosolic proteasome and, thus, extend the quality control repertoire of these ER proteins to include soluble proteins destined for the lysosome.

\section{Methods}

Materials. $\left[{ }^{35} \mathrm{~S}\right]$ Methionine/cysteine $(7.18 \mathrm{mCi} / 0.5 \mathrm{ml})$ and $\left[{ }^{14} \mathrm{C}\right] \delta$ aminolevulinic acid $\left(\left[{ }^{14} \mathrm{C}\right] \delta\right.$ ALA) $(0.25 \mathrm{mCi} / 2.5 \mathrm{ml})$ were obtained from Amersham Life Sciences Products (Arlington Heights, IL). Heat- 
killed, formalin-fixed protein A bearing Staphylococcus aureus (Pansorbin cells) were purchased from Calbiochem (San Diego, CA). Restriction endonucleases, T4 DNA ligase, calf-intestinal alkaline phosphatase (CIP), TaqI polymerase, and corresponding buffers were obtained from either Promega Co. (Madison, WI) or New England Biolabs, Inc. (Beverly, MA). Oligonucleotide primers were obtained from the DNA Core Facility at the University of Iowa (Iowa City, Iowa). $\mathrm{H}_{2} \mathrm{O}_{2}$ was purchased from Mallinckrodt Chemical Inc. (Paris, KY). Sequenase version 2.0/dideoxy sequencing kit, FBS, and RPMI 1640 ( \pm L-methionine) were purchased from Gibco Life Technologies (Gaithersburg, MD). $N$-glycanase F ( $N$-GF) and endoglycosidase $\mathrm{H}$ (endo $\mathrm{H}$ ) were obtained from Boehringer Mannheim (Indianapolis, IN). All other reagents were purchased from Sigma Chemical Co. (St. Louis, MO).

Identification of a missense mutation in patient BS. Heparinized, venous blood was obtained from individuals for routine screening in accordance with a protocol approved by the Institutional Review Board for Human Subjects at the University of Iowa (Iowa City, Iowa), and PMNs were isolated as described previously, using Hypaque-Ficoll density gradient separation after dextran sedimentation (15). Related individuals with variations of partial to complete MPO deficiency were identified both by enzymatic analysis and immunoblotting and then screened via exon mapping as described previously $(11,16)$. Nucleotide sequencing of MPO exon 4 in patients BS, GS, $\mathrm{CJ}$, and $\mathrm{AJ}$ revealed an $\mathrm{A} / \mathrm{G}$ missense mutation at nucleotide 681 (data not shown).

Site-directed mutagenesis. The Y173C mutation was created using PCR as described previously (11). A full-length cDNA for MPO previously cloned into pBluescript SK (Stratagene, La Jolla, CA) was used as template for site-directed mutagenesis. Overlap extension with PCR using forward primers ( ${ }^{249}$ TGGAAGTCTCCGACCGTATACCGGTCTTA $\left.{ }^{278}\right)$ and $\left({ }^{675}\right.$ ACAAATGCCGCACCATCACCGGAT $\left.{ }^{699}\right)$ and reverse primers $\left({ }^{667} \mathrm{CCTCGTCCTGTTTACGG-}\right.$ CGTGG $\left.^{688}\right)$ and $\left({ }^{943}\right.$ GGTGAAGTCGAGGTCGTGG $\left.{ }^{961}\right)$ generated a 696-bp cDNA fragment (position of the nucleotide replacement is underlined) with an $\mathrm{A} / \mathrm{G}$ substitution predicting a Y173C replacement in MPO. The fragment was digested with StuI and BclI (product, $493 \mathrm{bp}$ ), cloned into the identical region of MPO cDNA in pBluescript, and then sequenced to confirm the correct nucleotide substitution. Subsequently, $\mathrm{MPO}_{\mathrm{Y} 173 \mathrm{C}} \mathrm{CDNA}$ in pBluescript was digested with NotI and HindIII and cloned into the mammalian expression vector pREP10 (Invitrogen, San Diego, CA).

Stable transfections in K562 cells. Both K562 cells transfected with cDNA encoding normal MPO (WT MPO) and $\mathrm{MPO}_{\mathrm{Y} 173 \mathrm{C}}$ were generated from transfected K562 cell lines (American Type Culture Collection, Rockville, MD) as described previously (11). K562 cells were grown in RPMI 1640 containing penicillin-streptomycin, $2 \mathrm{mM}$ L-glutamine, and $10 \% \mathrm{FBS}$ and passaged when confluent. $8 \times 10^{6} \mathrm{log}$ phase cells were washed in unsupplemented RPMI 1640, resuspended in $0.5 \mathrm{ml}$ RPMI 1640 , and electroporated $(300 \mathrm{~V}, 960 \mu \mathrm{Fd})$ with $20 \mu \mathrm{g}$ pREP10 plasmid containing either WT-MPO or MPO $\mathrm{Y}_{173 \mathrm{C}}$ DNA and $10 \mu \mathrm{g}$ of salmon sperm carrier DNA in Hepes/ $\mathrm{NaCl}$. Stable transfectants were selected using $150 \mu \mathrm{g} / \mathrm{ml}$ hygromycin (Calbiochem) $48 \mathrm{~h}$ after transfection and stable lines expressing the desired protein for up to 6 wk were obtained $72 \mathrm{~h}$ after selection.

Metabolic labeling and immunoprecipitation of $M P O$ and $M P O_{Y 173 C}$. Metabolic labeling of transfected cell lines was performed as described previously (11). Briefly, $2 \times 10^{6}$ WT-MPO- and/or $\mathrm{MPO}_{\mathrm{Y}_{173 \mathrm{C}}}$-transfected K562 cells were washed in PBS and then reseeded in 6-well tissue culture dishes in methionine-free RPMI 1640 (containing $10 \%$ dialyzed FBS) to $5 \times 10^{5} \mathrm{cells} / \mathrm{ml}$. When indicated, proteasome inhibitors (from $50 \mathrm{mM}$ stocks in DMSO) were added during the incubation in methionine-free media and were present for the duration of the chase period. For experiments in which it was necessary to inhibit glycosylation, cells were incubated for $4 \mathrm{~h}$ in the presence of $5 \mu \mathrm{g} / \mathrm{ml}$ tunicamycin (TM) before metabolic labeling. After incubation at $37^{\circ} \mathrm{C}$ for $60 \mathrm{~min}$ in methionine-free media, cells were pulse-labeled for $60 \mathrm{~min}$ with $25 \mu \mathrm{Ci} / \mathrm{ml}\left[{ }^{35} \mathrm{~S}\right]$ methionine and then chased for indicated time periods with $1 \mathrm{mM}$ cold methionine. Cells were centrifuged at $500 \mathrm{~g}$ for $6 \mathrm{~min}$ at $25^{\circ} \mathrm{C}$ and then clarified culture media were saved for parallel immunoprecipitations. Cells were resuspended in lysis buffer (Tris-buffered saline [TBS], $\mathrm{pH}$ 7.5, containing $0.5 \mathrm{mg} / \mathrm{ml}$ leupeptin and pepstatin A, $0.5 \%$ CETAB, and $1.0 \%$ Triton X-100) with 1.0-2.0 mM PMSF and solubilized on ice for 20 min. Insoluble material was removed by briefly clarifying the lysate in a microcentrifuge (15 s at $12,000 \mathrm{rpm})$, which was then precleared with $7 \mu \mathrm{l}$ of nonimmune rabbit serum (rotation at $4^{\circ} \mathrm{C}$ for $30 \mathrm{~min}$ ) followed by $50 \mu \mathrm{l}$ of washed Pansorbin protein A (rotation at $4^{\circ} \mathrm{C}$ for an additional $30 \mathrm{~min}$ ). The lysate was clarified again to remove immune complexes (5 min at 12,000 rpm) and then diluted to $1.26 \mathrm{ml}$ with $50 \mathrm{mM}$ Tris- $\mathrm{Cl}$ (pH 7.4) containing $190 \mathrm{mM} \mathrm{NaCl}$ and $2.5 \%$ Triton X-100 (dilution buffer). Generally, 5-7 $\mu$ l of primary antibody ( $7 \mu \mathrm{l}$ of rabbit anti-MPO antibody, $7 \mu$ l of rabbit anti-CRT antibody, or $5 \mu \mathrm{l}$ of rabbit anti-CLN antibody [kindly provided by Dr. David B. Williams, University of Toronto, Toronto, Canada]) was added to cell lysates or to $1.26 \mathrm{ml}$ of cell-conditioned culture medium, and the immunoprecipitates were rotated for $4 \mathrm{~h}$ or overnight at $4^{\circ} \mathrm{C}$. Subsequently, $50 \mu \mathrm{l}$ of washed Pansorbin protein A were incubated with the immune complexes for $30 \mathrm{~min}$ and then pelleted as above. Immune complexes were washed sequentially in TBS (pH 7.5) containing $0.5 \%$ Triton X-100, TBS containing $0.5 \%$ Triton X-100 and $2.0 \mathrm{M}$ urea, TBS containing $0.5 \%$ Triton X-100 and $1 \mathrm{mg} / \mathrm{ml} \mathrm{BSA}$, and once in TBS alone.

For sequential immunoprecipitations used in the analysis of CLN-MPO or CRT-MPO complexes, Pansorbin protein A immune complexes obtained after precipitation with either CRT or CLN antibodies were washed, resuspended in $100 \mu \mathrm{l}$ of TBS containing $1.0 \%$ SDS, heated to $100^{\circ} \mathrm{C}$ for $5 \mathrm{~min}$, and then cooled immediately on ice. After clarification as described above, supernatants were transferred to fresh tubes, diluted 1:10 in dilution buffer, and then precipitated with antibody to MPO as described above. Samples were resolved by 5-20\% SDS-PAGE (see below).

For analysis of heme incorporation into WT-MPO or $\mathrm{MPO}_{\mathrm{Y} 173 \mathrm{C}}$, cells were prepared as described above, pulse-labeled with $14.3 \mu \mathrm{Ci} / \mathrm{ml}$ of $\left[{ }^{14} \mathrm{C}\right] \delta$ ALA for $24 \mathrm{~h}$ in RPMI 1640 containing 5\% FBS, and MPO was immunoprecipitated.

$\mathrm{N}$-GF and endo $H$ digestions. $20 \mu \mathrm{l}$ of sucrose gradient fractions was denatured by heating in the presence of 1\% SDS and then diluted 10 times with the appropriate enzyme buffer. Digestions with $\mathrm{N}$-GF or endo $\mathrm{H}$ were performed using $0.5 \mathrm{mU} \mathrm{N}$-GF and $10 \mathrm{mU}$ endo $\mathrm{H}$, respectively, for $1 \mathrm{~h}$ at $37^{\circ} \mathrm{C}$ as per the manufacturer's instructions. Alternatively, immunoprecipitated samples were washed and then resuspended in the appropriate enzyme buffer, heat-denatured in the presence of $0.2 \%$ SDS, and then digested. $6 \times$ SDS-sample buffer was added to digestions and samples were resolved by SDS-PAGE.

MPO activity. K562 cells or transfected K562 cells were seeded at $2 \times 10^{5}$ cells $/ \mathrm{ml} \pm 2 \mu \mathrm{g} / \mathrm{ml}$ hemin chloride and then assayed for peroxidase activity $48 \mathrm{~h}$ later as previously described (11). Briefly, cells were washed in PBS and then resuspended in TBS ( $\mathrm{pH} 7.5)$ containing $0.1 \%$ Triton X-100 to $6 \times 10^{7}$ cells $/ \mathrm{ml}$ and kept on ice until use. Reaction mixtures included $40 \mu \mathrm{l}$ of lysed cells and $25 \mu \mathrm{l}$ of $10 \mathrm{mg} / \mathrm{ml}$ orthodianisidine in $10 \mathrm{mM}$ sodium phosphate $(\mathrm{pH}$ 6.0) containing $0.03 \% \mathrm{H}_{2} \mathrm{O}_{2}$. Kinetic consumption of $\mathrm{H}_{2} \mathrm{O}_{2}$ was monitored continuously for $60 \mathrm{~s}$ at $460 \mathrm{~nm}$ using a spectrophotometer (DV 640; Beckman Instruments, Palo Alto, CA) and $V_{\max }$ was calculated automatically.

Subcellular fractionation of transfected K562 cells. K562 cells transfected with WT-MPO or MPO ${ }_{\mathrm{Y} 173 \mathrm{C}}$ constructs were seeded at $2 \times 10^{5}$ cells $/ \mathrm{ml}$ in culture medium containing $2 \mu \mathrm{g} / \mathrm{ml}$ of hemin chloride and cultured for $60 \mathrm{~h} .1 .5 \times 10^{7}$ cells were washed once in $30 \mathrm{ml}$ of PBS and $\mathrm{N}_{2}$-cavitated in $0.5 \mathrm{ml}$ of relaxation buffer as described by Borregaard et al. (17). Cavitates were loaded atop a $10-60 \%$ continuous sucrose gradient, centrifuged at 35,000 rpm (SW41 rotor; Beckman Instruments) $\left(151,000 \mathrm{~g} \mathrm{r}_{\mathrm{av}}\right)$ for $15 \mathrm{~h}$ at $4^{\circ} \mathrm{C}$, and 0.5 -ml fractions were collected from the bottom of each tube. Assays for cytochrome $c$ re- 
ductase and $\beta$-glucuronidase, markers for the ER and lysosome, respectively, were performed as described previously $(18,19)$. The distribution of protein in the gradient was measured by the BCA protein assay (Pierce, Inc., Rockford, IL). To analyze WT-MPO, MPO $_{\mathrm{Y} 173 \mathrm{C}}$, CRT, and $\beta$-COP distribution, $20 \mu \mathrm{l}$ of each fraction was mixed 1:1 with $2 \times$ SDS sample buffer, resolved by $10 \%$ SDS-PAGE, and then immunoblotted with rabbit anti-MPO, anti-CRT, or anti- $\beta-C O P$ (clone M3A5; Sigma Chemical Co.) antibodies. Immunoblots were developed using an enhanced chemiluminescence detection system (SuperSignal Substrate; Pierce, Inc.) according to the manufacturer's instructions.

$S D S-P A G E$ and autoradiography. Immunoprecipitations were routinely resuspended in $60 \mu \mathrm{l}$ of SDS sample buffer containing 2 -mercaptoethanol and heated for $3 \mathrm{~min}$ at $100^{\circ} \mathrm{C}$. After clarification (5 min at $12,000 \mathrm{rpm}$ ), $30 \mu \mathrm{l}$ of sample was resolved by $5-20 \%$ SDSPAGE and gels were fixed, dried, and then exposed to Kodak X-Omat film for $2-6 \mathrm{~h}\left(\left[{ }^{35} \mathrm{~S}\right]\right.$ methionine $)$ or $14 \mathrm{~d}\left(\left[{ }^{14} \mathrm{C}\right] \delta \mathrm{ALA}\right)$ at $-80^{\circ} \mathrm{C}$. For comparing reduced versus nonreduced proteins, samples prepared with or without $25 \mathrm{mM}$ of DTT were resolved by $8 \%$ SDS-PAGE. $\left[{ }^{35} \mathrm{~S}\right]$ Methionine gels were quantitated using a PhosphorImager (SF; Molecular Dynamics, Sunnyvale, CA) and $\left[{ }^{14} \mathrm{C}\right] \delta$ ALA gels via a densitometer (model GS-9000U Flying Spot; Shimadzu, Kyoto, Japan).

\section{Results}

Identification of a genotypically distinct form of MPO deficiency. During routine laboratory screening, a 27-yr-old female (SS) was found to have partial deficiency of MPO. Immunoblot analysis of PMNs isolated from SS revealed the presence of $90-\mathrm{kD}$ MPO precursors and $\sim 25 \%$ of the normal amount of mature MPO subunits (data not shown). Amplicons of exon 10 were resistant to digestion with BglII, indicating SS did not possess the R569W missense mutation previously identified as a cause of hereditary MPO deficiency $(11,16)$. The father of SS, BS, was completely MPO-deficient and his PMNs lacked mature 59-kD MPO species and peroxidase activity (Fig. $1 A$ ). Genomic sequencing of BS's DNA identified a guanine/adenine substitution at nucleotide $681\left(\mathrm{~A}^{681} / \mathrm{G}\right)$ in exon 4 of one allele, whereby tyrosine would be replaced by cysteine at codon 173 (Y173C). The same mutation was present in family members CJ, GS, and AJ (Fig. $1 B$ ). Like BS, all three of these offspring were heterozygous for Y173C and had reduced PMN peroxidase activity and correspondingly reduced levels of mature MPO (Fig. 1, $A$ and $B$ ). Based on the distribution of peroxidase deficiency and of the Y173C mutation in his family tree, BS must have two mutant alleles, Y173C and an abnormality that has not yet been unidentified (Fig. 1, $A$ and $B$ ). In contrast to BS, GS, CJ, and AJ have partial MPO deficiency and, thus, must possess one allele encoding normal MPO.

The Y173C substitution lies between C167 and C180 (positions 1 and 14 in the mature $13.5-\mathrm{kD}$ subunit), two residues demonstrated by crystal structure analysis of MPO to be linked by a disulfide bond (20). Interposition of an additional cysteine at position 173 could form novel and/or might disrupt normal disulfide bonds during biosynthesis and, thus, create misfolded MPO precursors (Fig. $2 A$ ). To assess the presence of additional or absence of normal disulfide linkages, electrophoretic mobilities of WT-MPO and $\mathrm{MPO}_{\mathrm{Y} 173 \mathrm{C}}$ were compared by nonreducing SDS-PAGE. Migration of precursor $\mathrm{MPO}_{\mathrm{Y} 173 \mathrm{C}}$ was retarded slightly in comparison to that of WTMPO precursor, consistent with the presence of aberrant disulfide bonds in $\mathrm{MPO}_{\mathrm{Y} 173 \mathrm{C}}$ (Fig. $2 \mathrm{~B}$ ). Disruption of normal disulfide bonds might perturb structural determinants required for
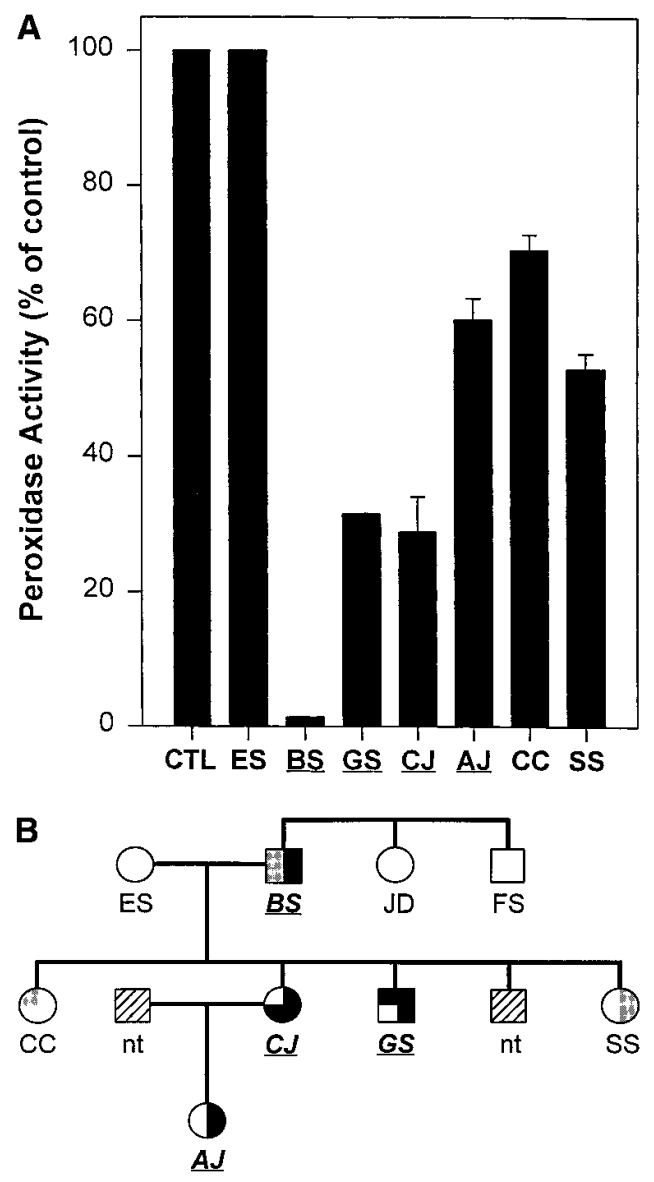

Figure 1. Hereditary MPO deficiency resulting from the Y173C mutation. (A) Peroxidase activity of PMNs from members of the $\mathrm{S}$ family with inherited MPO deficiency compared with that of healthy control subjects $(C T L)$. (B) Sequencing of genomic DNA from members of the S family identified the Y173C mutation. Subjects with Y173C (black) were compound heterozygotes, the other allele being normal (white) or an unidentified mutation (gray). The peroxidase activity of PMNs from a given subject is represented by the relative amount of the symbol that is white (e.g., ES has $100 \%$ activity whereas BS has no activity). Cross-hatched squares indicate individuals not tested $(n t)$. Results are expressed as the mean $\pm \mathrm{SD}$ of two to three separate trials.

proper folding and therefore compromise normal biosynthesis and/or intracellular compartmentalization.

Processing of $M P O_{Y 173 C}$. To characterize the impact of Y173C on MPO biosynthesis and processing, we expressed $\mathrm{MPO}_{\mathrm{Y} 173 \mathrm{C}}$ and WT-MPO in the human hematopoietic cell line K562. Both WT-MPO and $\mathrm{MPO}_{\mathrm{Y} 173 \mathrm{C}}$ transfectants produced similar quantities of $90-\mathrm{kD}$ MPO after pulse-labeling and chase intervals as long as $8 \mathrm{~h}$ (Fig. $3 \mathrm{~A}$ ). However, the chase period revealed three significant differences in the cellular fate of $\mathrm{MPO}_{\mathrm{Y} 173 \mathrm{C}}$ in comparison with that of normal MPO.

First, cells expressing normal MPO constitutively secreted a fraction of their MPO precursor, as demonstrated previously $(11,12)$. The secreted MPO precursor was partially resistant to digestion with endo $\mathrm{H}$, indicating these species traversed the Golgi and underwent modification of their oligosaccharide sidechains from high-mannose to complex forms (Fig. $3 \mathrm{~B}$ ). In 
A wt-MPO 1- C-P-E-Q-D-K-Y-R-T-I-T-G-M-C-14

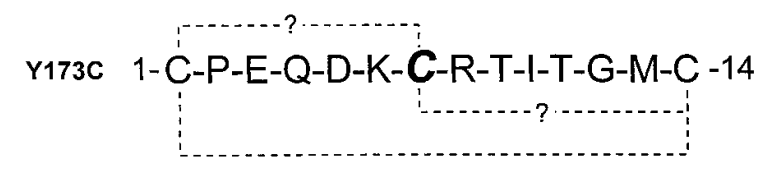

B

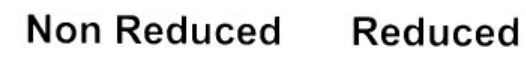

90-kDa-

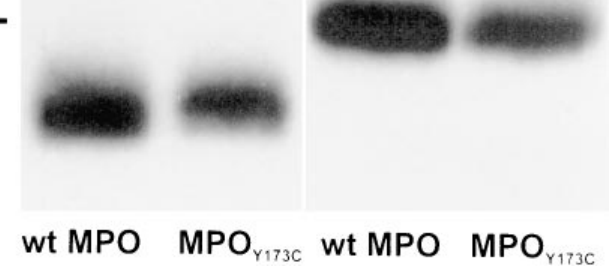

Figure 2. Comparison of disulfide bonds in WT MPO and $\mathrm{MPO}_{\mathrm{Y} 173 \mathrm{C}}$. (A) The crystal structure of MPO (20) indicates that a disulfide bond exists between residues $\mathrm{C} 1$ and $\mathrm{C} 14$ (C167 and C179 of the $90-\mathrm{kD}$ precursor) in the mature 13.5-kD MPO light subunit. The Y173C mutation (enlarged and italicized) is interposed between the linked cysteines and might perturb normal WT-MPO disulfide bridging. (B) WT-MPO and $\mathrm{MPO}_{\mathrm{Y} 173 \mathrm{C}}$ transfectants were pulse-labeled with $\left.{ }^{[35} \mathrm{S}\right]$ methionine, immunoprecipitated with $\alpha \mathrm{MPO}$, and then subjected to either reducing or nonreducing SDS-PAGE as indicated. Results comparing reducing versus nonreducing SDS-PAGE are representative of three separate experiments.

contrast, cells expressing $\mathrm{MPO}_{\mathrm{Y} 173 \mathrm{C}}$ failed to secrete any MPOrelated peptide even after $24 \mathrm{~h}$ of chase (Fig. $3 A$ ). Cell-associated MPO precursors either from WT-MPO or $\mathrm{MPO}_{\mathrm{Y} 173 \mathrm{C}}$ transfectants remained endo $\mathrm{H}$-susceptible (Fig. $3 B$ ). The inability of the $\mathrm{MPO}_{\mathrm{Y} 173 \mathrm{C}}$ transfectants to secrete MPO species did not reflect differential glycosylation as initial glycosylation of both $\mathrm{MPO}_{\mathrm{Y} 173 \mathrm{C}}$ and WT-MPO appeared identical when the products of transcription-translation assays in the presence of microsomal membranes were analyzed (Fig. $3 C$ ). Taken together these findings suggest that in contrast to the normal processing events, the $90-\mathrm{kD}$ MPO precursor synthesized in $\mathrm{MPO}_{\mathrm{Y} 173 \mathrm{C}}$ transfectants did not enter the secretory pathway and did not undergo maturation of the oligosaccharide sidechains in the Golgi.

Second, proteolytic maturation of precursor forms into subunits of lysosomal MPO differed in the two cell lines. After $8 \mathrm{~h}$ of chase, significant amounts of precursor had been processed to mature MPO in cells expressing WT-MPO, demonstrated by immunoprecipitation of the 59-kD heavy subunit of mature MPO after $24 \mathrm{~h}$ of chase (Fig. $3 \mathrm{D}$, left). In contrast, cells expressing $\mathrm{MPO}_{\mathrm{Y} 173 \mathrm{C}}$ did not generate subunits of mature MPO, an observation consistent with the phenotype of affected patients. Based on the failure to generate the lysosomal form of MPO in the $\mathrm{MPO}_{\mathrm{Y} 173 \mathrm{C}}$, we anticipated that the cells would also fail to incorporate heme into apoproMPO and would, thus, lack peroxidase activity.
In comparison to untransfected K562 cells, cells expressing WT-MPO had significant peroxidase activity, which was augmented nearly three times when cells were grown in the presence of hemin chloride, as described previously (11) (Table I). Unexpectedly, lysates derived from $\mathrm{MPO}_{\mathrm{Y} 173 \mathrm{C}}$ transfectants also exhibited MPO activity that was augmented two times when cells were grown in the presence of hemin, but this activity was significantly less than that of transfectants expressing normal MPO (Table I). In contrast to the observed phenotype in MPO-deficient individuals, these data suggest that $\mathrm{MPO}_{\mathrm{Y} 173 \mathrm{C}}$ was processed to a heme-containing enzyme, albeit less efficiently than in transfectants expressing normal MPO. Thus, although $\mathrm{MPO}_{\mathrm{Y} 173 \mathrm{C}}$ was not processed to mature MPO, $\mathrm{MPO}_{\mathrm{Y} 173 \mathrm{C}}$ cells had detectable peroxidase activity, suggesting that some of the mutant apoprotein was processed to the enzymatically active, heme-containing proenzyme.

To test this hypothesis, we assessed heme insertion by following the incorporation of $\left[{ }^{14} \mathrm{C}\right] \delta$ ALA-labeled prosthetic groups in MPO-related proteins. WT transfectants incorporated $\left[{ }^{14} \mathrm{C}\right] \delta$ ALA into the functional heme groups of $90-\mathrm{kD}$ proMPO and the 59-kD heavy subunit of mature MPO, as observed previously (Fig. 3 D) $(11,21)$. By comparison, $\mathrm{MPO}_{\mathrm{Y} 173 \mathrm{C}}$ transfectants also incorporated heme into $90-\mathrm{kD}$ apoproMPO, thereby generating proMPO, but not into a 59$\mathrm{kD}$ mature MPO heavy subunit (Fig. $3 D$ ). Less proMPO $\mathrm{Y}_{\mathrm{Y} 173 \mathrm{C}}$ was detected in comparison to that in normal cells, either because heme insertion was less efficient in the mutant $(\sim 30.8 \%$ of that observed in normal cells) and/or because proMPO ${ }_{\mathrm{Y} 173 \mathrm{C}}$ was less stable and/or had a shorter half-life than did WTproMPO (Fig. $3 D$ ). In either case, these data suggest that the peroxidase activity exhibited by $\mathrm{MPO}_{\mathrm{Y} 173 \mathrm{C}}$ transfectants could be attributed to the presence of the proform of the mutant protein and confirms that the Y173C mutation adversely affected the stability and subsequent proteolytic maturation of proMPO.

In addition to the aberrant secretion and proteolytic processing seen in $\mathrm{MPO}_{\mathrm{Y} 173 \mathrm{C}}$ transfectants, the mutant protein appeared to decay more rapidly than did normal MPO. After $24 \mathrm{~h}$ of chase, cells expressing $\mathrm{MPO}_{\mathrm{Y} 173 \mathrm{C}}$ had a fivefold reduction $(19.4 \pm 7.1 \%$ of WT) in MPO-related protein intracellularly, relative to cells expressing WT-MPO, and did not secrete MPO-related protein. Based on these and previous observations (22), we conclude that proMPO, once formed in the ER, has two potential fates: (a) to undergo proteolytic processing to the mature form of MPO destined for the azurophilic granule, or $(b)$ to enter the secretory pathway with the associated carbohydrate modification during passage through the Golgi

Table I. Peroxidase Activities of WT-MPO and MPO ${ }_{Y 173 C}$

\begin{tabular}{lrr}
\hline \multicolumn{1}{c}{ Cell line } & \multicolumn{1}{c}{$(-)$ Hemin } & $(+) 2 \mu \mathrm{g} / \mathrm{ml} \mathrm{hemin}$ \\
\hline pREPMPO & $1.0 \pm 0.11(6)$ & $2.81 \pm 0.11(4)$ \\
pREPMPO $_{\text {Y173C }}$ & $0.68 \pm 0.15(4)$ & $1.18 \pm 0.06(6)$ \\
K562 (control) & $0.36 \pm 0.11(3)$ & $0.39 \pm 0.05(3)$ \\
\hline
\end{tabular}

Peroxidase activity was quantitated as described in Methods. The pREPMPO (WT-MPO) transfectant was given a value of 1.0 and all results are expressed relative to that value. Results are expressed as the mean \pm SD of $n$ trials from three separate experiments. (The number of trials $[n]$ is in parentheses next to each data set.) 
A

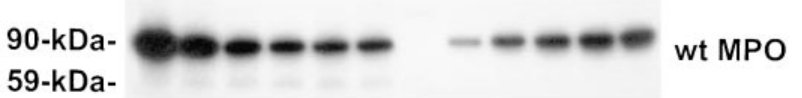

(n)

59-kDa-

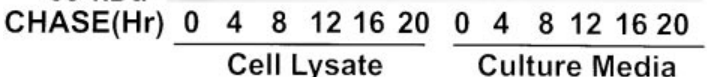

B

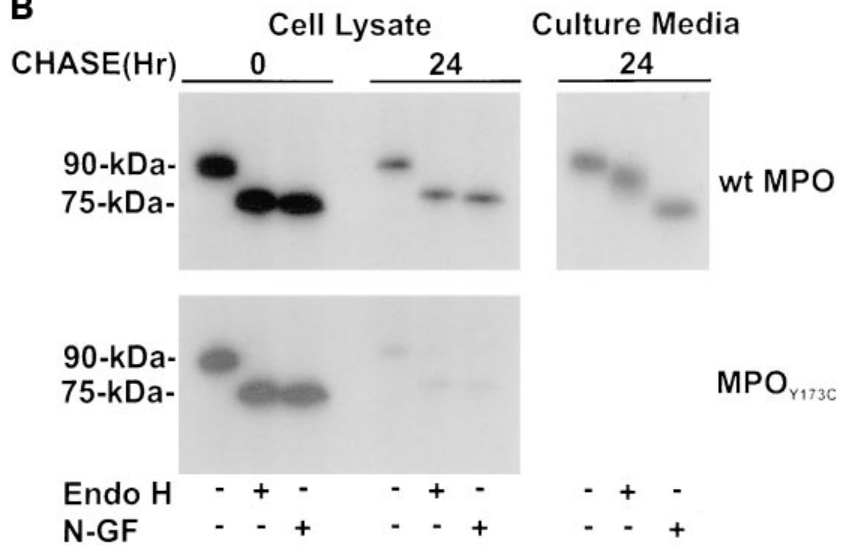

C

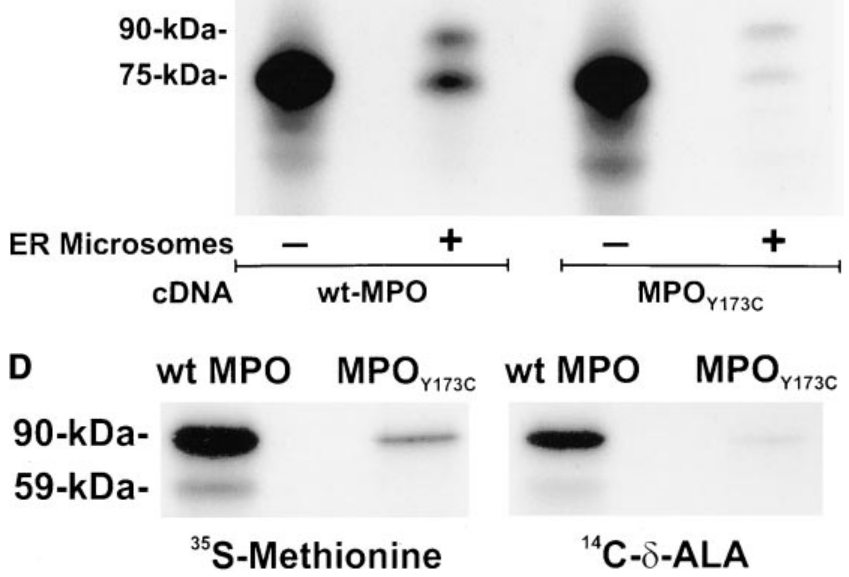

Figure 3. Biosynthetic processing of WT MPO and $\mathrm{MPO}_{\mathrm{Y} 173 \mathrm{C}} \cdot(A)$ Transfected K562 cells expressing either WT MPO or $\mathrm{MPO}_{\mathrm{Y} 173 \mathrm{C}}$ were pulse-labeled with $\left[{ }^{35} \mathrm{~S}\right]$ methionine and then chased with cold methionine for the indicated time periods. After the chase period, cells and culture media from each transfectant were immunoprecipitated with $\alpha \mathrm{MPO}$ and the resulting immunoprecipitate resolved by SDSPAGE and autoradiography. (B) WT-MPO and $\mathrm{MPO}_{\mathrm{Y} 173 \mathrm{C}}$ transfectants were pulse-labeled with $\left.{ }^{35} \mathrm{~S}\right]$ methionine, chased for $24 \mathrm{~h}$, and the resulting $\alpha \mathrm{MPO}$ immunoprecipitations were digested with either endo $\mathrm{H}$ or $N$-GF. $(C)$ The cDNA for WT MPO or $\mathrm{MPO}_{\mathrm{Y} 173 \mathrm{C}}$ was transcribed/translated in vitro using a rabbit reticulocyte lysate assay as described previously (36). In the absence (-) of ER microsomes, the WT and/or 75-80 kD mutant core protein was observed to be translated equally. Glycosylated forms of the initial transcripts were generated when translation was initiated in the presence $(+)$ of ER microsomes as indicated, and those of the WT or mutant were observed to be of identical size $(\sim 90-\mathrm{kD})$. ( $D)$ To identify heme-containing MPO-related precursors, transfected cells were pulse-labeled with $\left.{ }^{35} \mathrm{~S}\right] \mathrm{methionine}$ and chased for $24 \mathrm{~h}(l e f t)$ or were continuously pulse-labeled for $24 \mathrm{~h}$ with $\left[{ }^{14} \mathrm{C}\right] \delta$ ALA and then immunoprecipitated with $\alpha$ MPO. Results are representative of three to five separate experiments. apparatus. Data from the pulse-chase biosynthetic labeling of $\mathrm{MPO}_{\mathrm{Y} 173 \mathrm{C}}$ suggest proMPO $\mathrm{Y} 173 \mathrm{C}_{\mathrm{C}}$ was unable to follow either of these routes and was, instead, eventually degraded.

Subcellular localization of MPO and MPOY173C in transfected $K 562$ cells. Since proMPO ${ }_{\mathrm{Y} 173 \mathrm{C}}$ was neither processed to mature protein nor secreted, we sought to identify its subcellular location using sucrose density gradient centrifugation. Fractions were collected and organelles identified by the presence of specific marker proteins, assessed enzymatically or immunochemically. ER (cytochrome $c$ reductase), lysosomes ( $\beta$-glucuronidase), and Golgi ( $\beta$-COP) were identified as were the distributions of MPO and CRT (Fig. 4, $A-C$ ). The subcellular distributions of the marker enzymes and WT-MPO derived from the transfected K562 cells were similar to those in PLB-985 cells, a cultured human promyelocytic cell line (23) (data not shown). Thus, the distribution of subcellular organelles in these sucrose density gradients was the same for cells either transfected with MPO cDNA or expressing endogenous MPO.

MPO-related species were identified immunochemically and included the $90-\mathrm{kD}$ precursors and the $59-\mathrm{kD}$ heavy subunit of mature MPO. In addition, the antiserum recognized a 69-kD protein (Fig. $4 C$, indicator) that was detected even in K562 cells that had not been transfected with cDNA for MPO. Since K562 cells express neither mRNA nor protein for MPO (24) this $69-\mathrm{kD}$ protein is not related to MPO, although its identity is unknown.

As observed in pulse-chase experiments, cells transfected with WT-MPO generated the 59-kD subunit and this species sedimented predominantly in fractions 10-16, coincident with the lysosomal marker $\beta$-glucuronidase (Fig. $4, B$ and $C$ ). In contrast, cells transfected with $\mathrm{MPO}_{\mathrm{Y} 173 \mathrm{C}}$ did not synthesize the 59-kD heavy subunit of mature MPO (Fig. $4 C$ ). The majority of both normal and mutant $90-\mathrm{kD}$ precursor MPO sedimented in fractions 5-12, correlating well with the distribution of the ER markers CRT and cytochrome $c$ reductase (Fig. 4, B and $C$ ).

The subcellular fractionation of WT-MPO differed from that of the mutant protein in the distribution of the $90-\mathrm{kD}$ MPO precursor. Fractions 16-17 of the WT-MPO gradient contained the $90-\mathrm{kD}$ precursor, whereas there was no MPOrelated protein in corresponding fractions from the $\mathrm{MPO}_{\mathrm{Y} 173 \mathrm{C}}$ gradient (Fig. 4, $B$ and $C$ ). Since $\mathrm{MPO}_{\mathrm{Y} 173 \mathrm{C}}$ transfectants did not secrete the $90-\mathrm{kD}$ precursor during biosynthesis (Fig. $3 A$ ), we reasoned that the $90-\mathrm{kD}$ precursor in fractions 16 and 17 of WT-MPO might represent exocytotic vesicles bound for secretion. However, none of the $90-\mathrm{kD}$ MPO from fractions 16 or 17 were resistant to digestion with endo $\mathrm{H}$ (Fig. $4 \mathrm{D}$ ), in contrast to the partially endo $\mathrm{H}$-resistant state of the secreted precursor (Fig. $3 \mathrm{~B}$ ). These fractions may represent a post-ER, prelysosomal compartment, although studies to determine the subcellular location of these fractions are ongoing. Nonetheless, these data suggest that $\mathrm{MPO}_{\mathrm{Y} 173 \mathrm{C}}$ failed to enter targeting pathways destined for the Golgi complex or the lysosome and instead remained associated with the ER.

Association of MPO ${ }_{Y 173 C}$ with CLN and CRT is abnormal. We have demonstrated previously that CRT functions as a molecular chaperone during MPO biosynthesis and associates specifically with apoproMPO (9). In addition, we have shown recently that CLN associates both with apoproMPO and proMPO (10). Glycosylation of normal MPO precursors is necessary for interaction with CRT or with CLN, as nonglyco- 


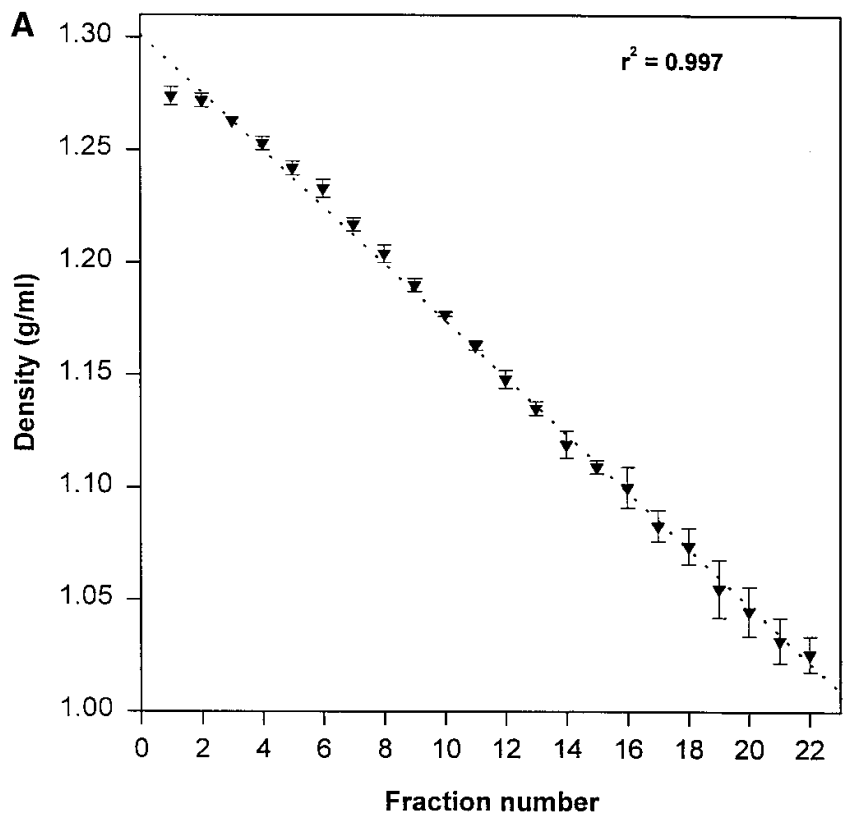

sylated forms synthesized in the presence of TM do not associate with either chaperone $(9,10)$. To determine whether these chaperones participate in the ER retention of $\mathrm{MPO}_{\mathrm{Y} 173 \mathrm{C}}$, we compared the association of CRT and CLN with WT-MPO and $\mathrm{MPO}_{\mathrm{Y} 173 \mathrm{C}}$ (Fig. 5, $A-E$ ). To determine if glycosylation of both WT-MPO and $\mathrm{MPO}_{\mathrm{Y} 173 \mathrm{C}}$ was required for association with CRT and/or CLN, we compared association of the chaperones with nonglycosylated WT and mutant MPO proteins synthesized in the presence of TM. Nonglycosylated precursors $(75-80 \mathrm{kD})$ of neither WT-MPO nor MPO $_{\mathrm{Y} 173 \mathrm{C}}$ associated with CRT or CLN, confirming our previous results from studies of the promyelocytic cell line, PLB 985 (9, 10) (Fig. $5 A$ ). WT-MPO in transfected K562 cells associated with CRT transiently and the apoproMPO-CRT complex was partially dissociated by $4 \mathrm{~h}$ (Fig. 5, $B$ and $C$ ). In contrast, the fraction of apoproMPO $_{\mathrm{Y} 173 \mathrm{C}}$ associated with CRT immediately after the pulse-labeling was reduced $(\sim 39.0 \%)$ in comparison to that of control cells and remained constant for up to $4 \mathrm{~h}$ of chase (Fig. $5, B$ and $C$ ). These data demonstrate that the $\mathrm{MPO}_{\mathrm{Y} 173 \mathrm{C}}-\mathrm{CRT}$ complex remained intact for prolonged periods, consistent with the interpretation that CRT retained the mutant protein within the ER, presumably for eventual degradation.

Similar results were obtained when the association of $\mathrm{MPO}_{\mathrm{Y} 173 \mathrm{C}}$ with CLN was studied (Fig. 5, $D$ and $E$ ). WT-MPO transiently associated with CLN, leaving only $10.2 \pm 1.9 \%$ of the initial complex after $4 \mathrm{~h}$ of chase (Fig. 5, $C$ and $D$ ). There was less precursor $\mathrm{MPO}_{\mathrm{Y} 173 \mathrm{C}}(\sim 37.2 \%$ less $)$ associated with CLN immediately after pulse-labeling. In addition, CLN associated with the $\mathrm{MPO}_{\mathrm{Y} 173 \mathrm{C}}$ precursor for a prolonged period during the chase (Fig. 5, $D$ and $E$ ). In contrast to the dissociation of CLN-MPO complexes observed with WT-MPO transfectants, at $4 \mathrm{~h}$ of chase, $81.0 \pm 0.4 \%$ of the initial CLN$\mathrm{MPO}_{\mathrm{Y} 173 \mathrm{C}}$ complex remained intact. Even at $24 \mathrm{~h}$ of chase there was still $40.1 \pm 7.9 \%$ of the initial complex remaining, compared to $2.8 \pm 1.3 \%$ of the complex remaining with WTMPO (Fig. 5, $D$ and $E$ ). Although $\mathrm{MPO}_{\mathrm{Y} 173 \mathrm{C}}$ was significantly degraded at $24 \mathrm{~h}$ of chase, much of the remaining mutant MPO species appeared complexed to CLN (Fig. 5, D and E). Collectively, these data indicate that the Y173C mutation adversely

C

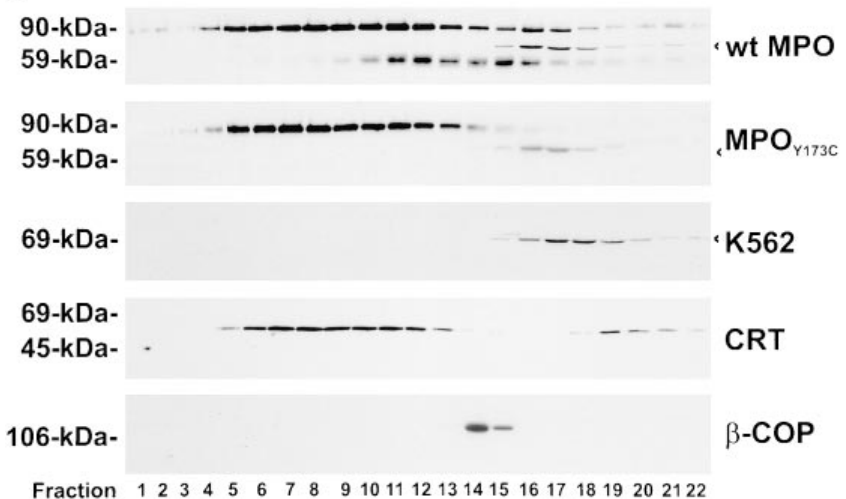

Figure 4. Subcellular fractionation of WT-MPO and $\mathrm{MPO}_{\mathrm{Y} 173 \mathrm{C}}$. Lysates of K562 cells expressing WT-MPO and MPO $_{\text {Y173C }}$ were separated by centrifugation on $10-60 \%$ sucrose gradients as described in Methods. $A$ and $B$ indicate density of fractions from the gradient (closed triangles), $\beta$-glucuronidase (open triangles) (lysosomal marker), and cyanide-insensitive cytochrome $c$ reductase activity (circles) (ER marker), respectively. (C) Gradient fractions were resolved by $10 \%$ SDS-PAGE and then probed with $\alpha$ MPO (WT MPO, $\mathrm{MPO}_{\mathrm{Y} 173 \mathrm{C}}$, and K562) or $\alpha \mathrm{CRT}$ and anti- $\beta-\mathrm{COP}$, as indicated. (D) 20 $\mu l$ of the indicated WT-MPO gradient fractions was digested with endo H, separated by SDS-PAGE, and the electroblots probed with $\alpha$ MPO. Digestion with $N$-GF yielded MPO protein of identical size to that cut with endo $\mathrm{H}$ (data not shown). The indicator marks the presence of a protein nonspecifically recognized by the MPO antiserum that is present in K562 cells that were not transfected with cDNA encoding MPO. The linearity plot $(A)$ is the mean \pm SD of two separate gradients. Results in $B$ and $C$ are from one experiment representative of at least three separate fractionation experiments, and those in $D$ are from one experiment representative of two separate experiments (fractionations). 
A
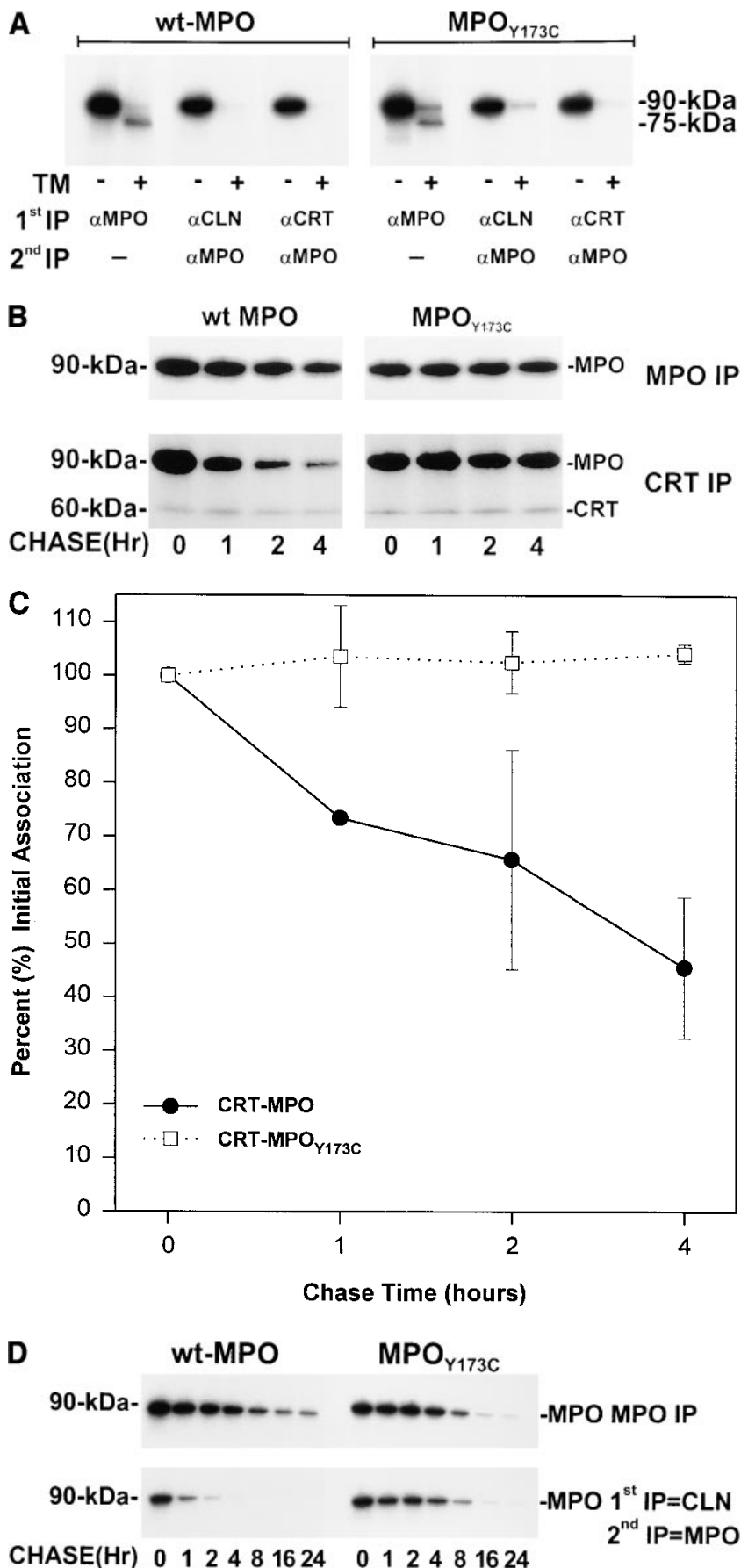

Figure 5. Association of WT-MPO and $\mathrm{MPO}_{\mathrm{Y} 173 \mathrm{C}}$ with $\mathrm{CRT}$ and CLN. (A) WT-MPO and MPO $_{\mathrm{Y} 173 \mathrm{C}}$ transfectants were cultured in the presence of $5 \mu \mathrm{g} / \mathrm{ml}$ of TM as indicated and then pulse-labeled with $\left[{ }^{35} \mathrm{~S}\right]$ methionine and immunoprecipitated with $\alpha \mathrm{MPO}$ or sequentially with $\alpha$ CRT or $\alpha$ CLN followed by $\alpha$ MPO. Autoradiograms of the sequential immunoprecipitations were exposed four to eight times longer than those of $\alpha \mathrm{MPO}$ to maximize detection of any coprecipitating 75-80 kD nonglycosylated MPO. Results are representative of two separate experiments. $(B-E) \mathrm{K} 562$ cells expressing WT MPO and $\mathrm{MPO}_{\mathrm{Y} 173 \mathrm{C}}$ were pulse-labeled with $\left[{ }^{35} \mathrm{~S}\right]$ methionine and then chased with cold methionine for the indicated time periods. Cell lysates were immunoprecipitated with either $\alpha \mathrm{MPO}$ or $\alpha \mathrm{CRT}$ ( $B$, as indicated) and subjected to 5-20\% SDS-PAGE and autoradiography. The amount of CRT coimmunoprecipitating with MPO (circles) or with $\mathrm{MPO}_{\mathrm{Y} 173 \mathrm{C}}$ (squares) was quantitated by PhosphorImager analysis $(C)$ and is the mean \pm SD of two to three separate experiments. Alterna- affected both the association as well as the dissociation of MPO precursors with the ER-resident chaperones CRT and CLN. Given the absence of cell-associated mature or secreted protein in $\mathrm{MPO}_{\mathrm{Y} 173 \mathrm{C}}($ Fig. $3 A$ ), we reasoned that prolonged association of the mutant protein with CRT and/or CLN may serve to retain the misfolded protein in the ER, which is incompetent for proteolytic processing and normal maturation.

$E R$ degradation of $M P O_{Y 173 C}$ is linked to the activity of the cytosolic proteasome. Since $\mathrm{MPO}_{\mathrm{Y} 173 \mathrm{C}}$ was retained in the ER, we examined the possibility that its degradation might be mediated by the cytosolic proteasome. We tested the ability of two peptide aldehyde $20 \mathrm{~S}$ proteasome inhibitors, $N$-acetylL-leucinyl-L-leucinyl-L-norleucinyl (ALLN) and $N$-acetylL-leucinal-L-leucinal-L-methional (ALLM), to block degradation of $\mathrm{MPO}_{\mathrm{Y} 173 \mathrm{C}}$. Although both ALLN and ALLM are also cysteine protease inhibitors, ALLM is significantly less potent in inhibiting the proteasome when compared with the activity of ALLN (25).

Immediately after the pulse-labeling, nearly identical amounts of $90-\mathrm{kD}$ MPO precursor were made in WT-MPO and $\mathrm{MPO}_{\mathrm{Y} 173 \mathrm{C}}$ transfectants (Fig. 6, lane 1). However, as noted previously (Fig. $3 \mathrm{~A}$ ), there was relatively less MPO precursor still present intracellularly at $24 \mathrm{~h}$ of chase in $\mathrm{MPO}_{\mathrm{Y} 173 \mathrm{C}}$ than in WT-MPO cells (Fig. 6, lane 3, compare top and bottom). The addition of $50 \mu \mathrm{M}$ of ALLN to $\mathrm{MPO}_{\mathrm{Y} 173 \mathrm{C}}$ transfectants significantly reduced degradation of the $90-\mathrm{kD}$ precursor and increased the level of intracellular protein to a level comparable to that observed in WT-MPO transfectants (Fig. 6, compare lane 4, bottom with lane 3, top). However, treating the cells with up to 10 times more ALLN did not further inhibit degra-

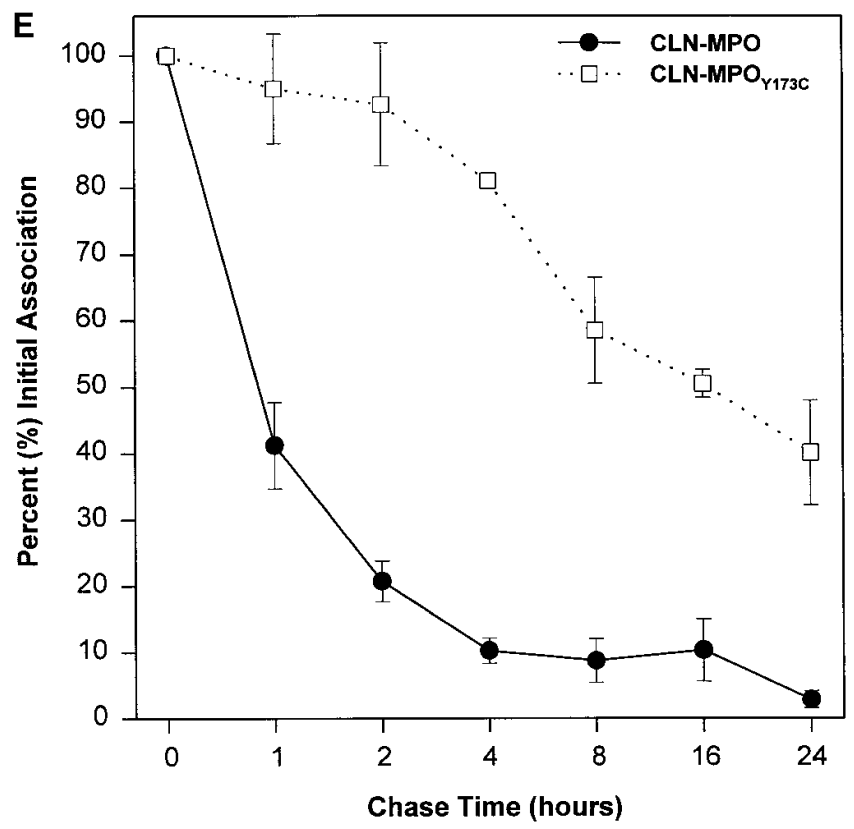

tively, cell lysates were immunoprecipitated with either $\alpha \mathrm{MPO}$ or sequentially with $\alpha \mathrm{CLN}$ followed by $\alpha \mathrm{MPO}(D$, as indicated) and subjected to $5-20 \%$ SDS-PAGE and autoradiography. The amount of CLN coimmunoprecipitating with MPO (circles) or with $\mathrm{MPO}_{\mathrm{Y} 173 \mathrm{C}}$ (squares) was quantitated by PhosphorImager analysis $(E)$ and results are expressed as the mean \pm SD of two to four separate experiments. 


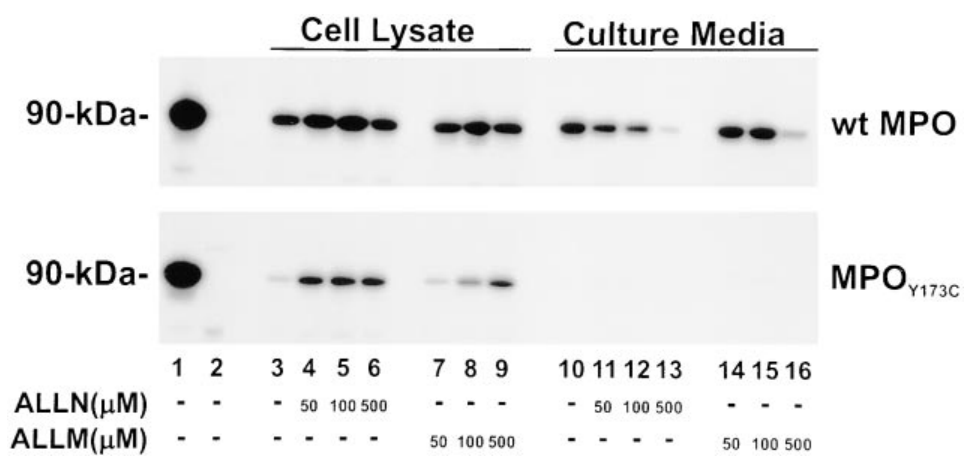

Figure 6. Degradation of $\mathrm{MPO}_{\mathrm{Y} 173 \mathrm{C}}$ is blocked by the proteasome inhibitor ALLN. Transfected K562 cells expressing either WT MPO or $\mathrm{MPO}_{\mathrm{Y} 173 \mathrm{C}}$ were pulse-labeled with $\left[{ }^{35} \mathrm{~S}\right] \mathrm{me}-$ thionine in the presence $(+)$ or absence $(-)$ of 50,100 , and $500 \mu \mathrm{M}$ of ALLN or ALLM, as indicated, and then chased with cold methionine for $24 \mathrm{~h}$. After the chase period, cells and culture media from each treatment were immunoprecipitated with $\alpha \mathrm{MPO}$. The resulting immunoprecipitate was resolved by SDS-PAGE and the proteins were visualized using autoradiography. Lanes 1 and 2 represent MPO immunoprecipitated from cell lysates immediately after the pulse label or the resulting supernatant, respectively, in the absence of a chase. Results are from one experiment representative of two separate experiments. dation nor did it correct the observed defects in secretion or proteolytic maturation seen in $\mathrm{MPO}_{\mathrm{Y} 173 \mathrm{C}}$ (Fig. 3, $A$ and $B$, and Fig. 6). In contrast to the effects of ALLN, ALLM was less effective in inhibiting degradation of $\mathrm{MPO}_{\mathrm{Y} 173 \mathrm{C}}$; at $50 \mu \mathrm{M}$ of ALLM, the degradation of mutant precursor was not inhibited. Only at very high concentrations $(>10 \times$ that of ALLN) was the reduction in degradation similar (Fig. 6, bottom compare lanes 4-6 with 7-9) to that observed with ALLN. The lack of secreted $90-\mathrm{kD}$ species or processing to mature subunits in $\mathrm{MPO}_{\mathrm{Y} 173 \mathrm{C}}$ transfectants treated with ALLN is consistent with our hypothesis that $\mathrm{MPO}_{\mathrm{Y} 173 \mathrm{C}}$ species were retained in the ER by association of these species with CRT and CLN en route to their degradation in the proteasome.

\section{Discussion}

We have identified a novel genotype, Y173C, underlying hereditary MPO deficiency and described its impact on MPO synthesis. As a result of these studies, we have made several new observations pertinent to the biosynthesis of MPO specifically but that likely have implications for protein synthesis and ER quality control in general. Our findings are summarized schematically in a model that contrasts the fates of normal and Y173C MPO gene products (Fig. 7).

In the ER, the normal MPO transcript is cotranslationally modified by $\mathrm{N}$-linked glycosylation and the resultant apoproMPO associates transiently with CRT and with CLN in succession (10). We have assigned this order of sequential association of apoproMPO with CRT and CLN based on our previous finding that CLN but not CRT associates with proMPO (10). Thus, it appears that chaperone association culminates in heme insertion and the conversion of apoproMPO into the enzymatically active precursor, proMPO. Once generated, proMPO can be directed toward the lysosome or into the secretory pathway. The former process involves budding from the ER and proteolytic processing in a prelysosomal, brefeldin-A-sensitive compartment (12). It is clear that only proMPO, and not apoproMPO, can undergo proteolytic processing into the subunits of mature MPO, since either inhibition of heme synthesis by succinyl acetone $(12,26,27)$ or mutations, such as that described previously in exon 10 (11), which impair heme insertion block proteolytic maturation. ProMPO not destined for the lysosome enters the constitutive secretory pathway via the Golgi complex, wherein modification of the oligosaccharide sidechains results in glycoproteins partially resistant to digestion with endo $\mathrm{H}$.
Like the normal MPO gene product, Y173C underwent cotranslational $\mathrm{N}$-linked glycosylation and association with CRT and with CLN in the ER. However the associations of the apoproMPO ${ }_{\mathrm{Y} 173 \mathrm{C}}$ with CRT and with CLN were prolonged, presumably due to aberrant folding of apopro$\mathrm{MPO}_{\mathrm{Y} 173 \mathrm{C}}$. Although heme was inserted into the mutant protein, the resultant proMPO $_{\mathrm{Y} 173 \mathrm{C}}$ failed to proceed along the pathway of normal MPO biosynthesis. In fact, proMPO ${ }_{\mathrm{Y} 173 \mathrm{C}}$ did not undergo proteolytic maturation into the lysosomal form of MPO nor did it enter the secretory pathway. Instead the mutant protein was degraded by a mechanism dependent on a functional cytosolic proteasome.

Several studies indicate that proteins previously thought to be degraded within the ER lumen are in fact transported in a retrograde fashion through the translocon and destroyed by the cytosolic proteolytic complex known as the proteasome $(25,28-31)$. Furthermore, recent studies of the cystic fibrosis transmembrane conductance regulator (CFTR) and a deletion mutant underlying cystic fibrosis (a phenylalanine deletion at codon 508 in the CFTR [ $\Delta$ F508]) have shown that ER degradation is facilitated by prolonged association of $\Delta \mathrm{F} 508$ with CLN (32) and that the mutant protein is subsequently proteolyzed by the ubiquitin/proteasome machinery $(25,28)$. Just as we found in our studies of the Y173C mutation of MPO, specific proteasome inhibitors inhibit degradation of the mutant CFTR precursor $(25,28)$. Thus, we believe that ER retention of proMPO $\mathrm{Y}_{\mathrm{Y} 173 \mathrm{C}}$ by CRT and CLN serves an important role in the quality control of MPO biosynthesis by myeloid cells.

In contrast to CFTR, which is a transmembrane protein, MPO and its precursors are soluble proteins, localized in the lumen of the lysosome and ER, respectively. Because MPO lacks a membrane-spanning domain, its mechanism for targeting to the proteasome may be different from that for CFTR or other integral membrane proteins. Based on our data the range of proteins degraded by the proteasome can be extended to include those destined for the lysosome. In addition, these studies represent the first demonstration that the ER/ proteasome degradation machinery functions in biosynthetically active human myeloid cells. It is probable that genotypes underlying other inherited myeloid disorders, such as X-linked chronic granulomatous disease $(33,34)$ and leukocyte adhesion deficiency syndrome (35), result from abnormal protein biosynthesis leading to ER/proteasome degradation. Characterization of such processes and determination of the mechanisms for ER retention and subsequent export await further study. 


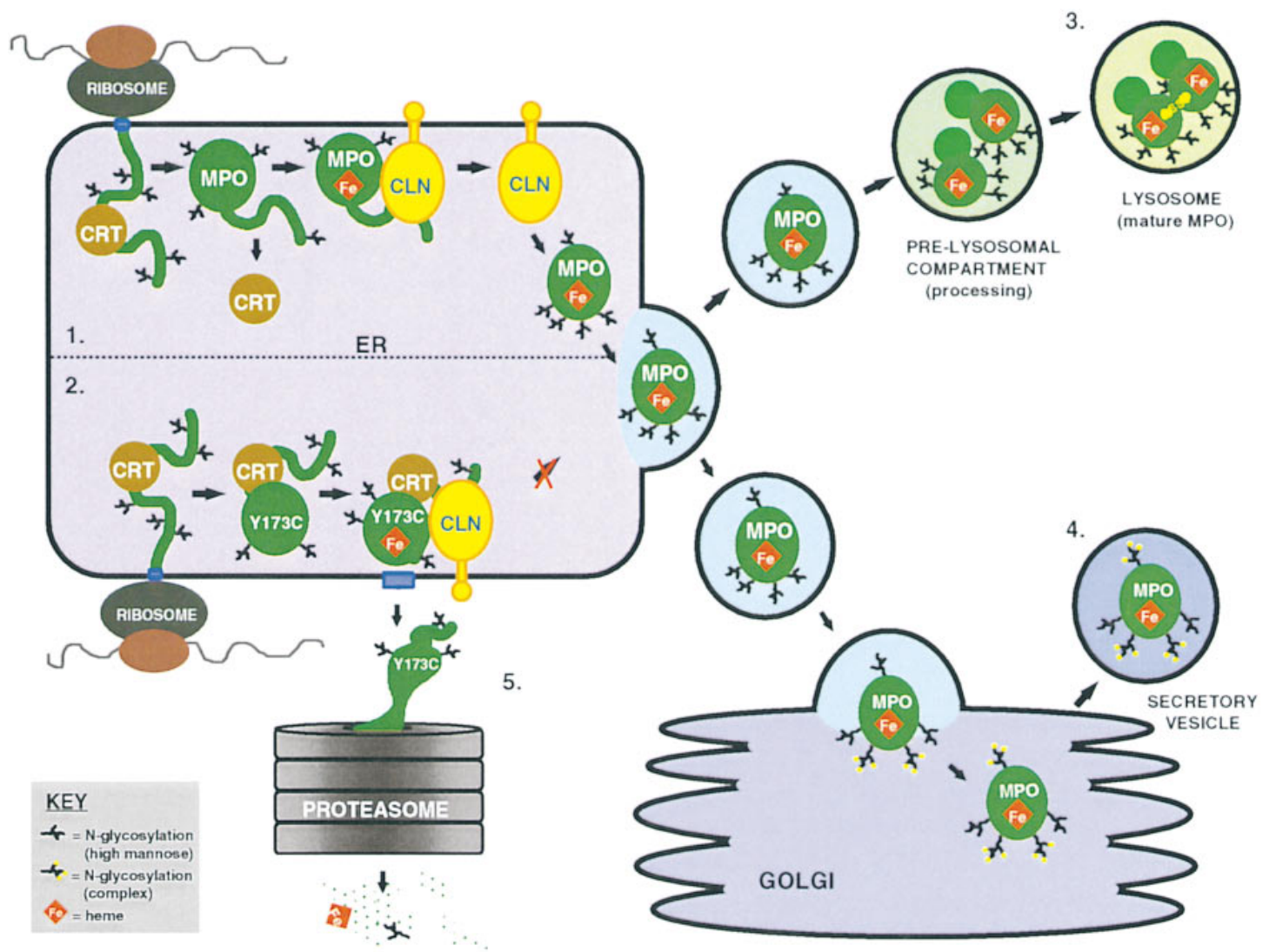

Figure 7. A model contrasting the biosynthesis and maturation of WT MPO and $\mathrm{MPO}_{\mathrm{Y} 173 \mathrm{C}}$. Both WT-MPO and $\mathrm{MPO}_{\mathrm{Y} 173 \mathrm{C}}$ are cotranslationally modified via the addition of five $N$-linked glycosylations and then associate with CRT ( 1 and 2 in the ER). Since in WT MPO CRT associates only with apoproMPO, normal apoproMPO must be released from CRT before heme insertion. Since CLN associates with apoproMPO as well as proMPO, the association of MPO precursors with CLN most likely follows dissociation of CRT-apoproMPO (1 in the ER). Normal proMPO then leaves the ER where it is targeted to either lysosomes (3) or the Golgi complex for secretion (4). In contrast, the precursor forms of $\mathrm{MPO}_{\mathrm{Y} 173 \mathrm{C}}$ associate in a prolonged fashion with both CRT and CLN (2). As a result, MPO $\mathrm{Y}_{173 \mathrm{C}}$ precursors are retained in the ER lumen for subsequent export to the cytosolic proteasome and degradation (5). Since MPO lacks a membrane-spanning region, it must associate with another protein, which is either membrane-associated (e.g., CRT) or an integral membrane protein (e.g., CLN), to mediate transport to the translocon and retrograde export to the cytosolic proteasome.

\section{Acknowledgments}

The authors gratefully acknowledge David B. Williams (Department of Biochemistry, University of Toronto, Toronto, Canada) for the generous gift of antibody to the COOH-terminal end of CLN. We thank Dr. Lee-Ann Allen (University of Iowa, Iowa City, Iowa) for her helpful suggestions and for her thoughtful critique of the manuscript. The authors also acknowledge Joe Reardon (Veterans Administration Medical Center, Iowa City, Iowa) for his expert photography and skill in the preparation of figures from autoradiograms.

This work was supported by Public Health Service Post-Doctoral Training Grant 5-T32-AI07343-09 (Frank R. DeLeo), Public Health Service Research Grant HL-53592 (William M. Nauseef), and a Veterans Administration Merit Review (William M. Nauseef).

\section{References}

1. Klebanoff, S.J. 1970. Myeloperoxidase: contribution to the microbicidal activity of intact leukocytes. Science. 169:1095-1097.

2. Klebanoff, S.J., and C.B. Hamon. 1972. Role of myeloperoxidase-mediated antimicrobial systems in intact leukocytes. J. Reticuloendothel. Soc. 12: $170-196$.

3. Robinson, J.M., and J.A. Badwey. 1995. The NADPH oxidase complex of phagocytic leukocytes: a biochemical and cytochemical view. Histochemistry. 103:163-180.
4. Hazen, S.L., F.F. Hsu, D.M. Mueller, J.R. Crowley, and J.W. Heinecke. 1996. Human neutrophils employ chlorine gas as an oxidant during phagocytosis. J. Clin. Invest. 98:1283-1289.

5. Hazen, S.L., F.F. Hsu, K. Duffin, and J.W. Heinecke. 1996. Molecular chlorine generated by the myeloperoxidase hydrogen peroxide chloride system of phagocytes converts low density lipoprotein cholesterol into a family of chlorinated sterols. J. Biol. Chem. 271:23080-23088.

6. Nauseef, W.M., I. Olsson, and K. Arnijots. 1988. Biosynthesis and processing of myeloperoxidase. A marker for myeloid cell differentiation. Eur. J. Haematol. 40:97-110.

7. Nauseef, W.M. 1990. Myeloperoxidase deficiency. Hematol. Pathol. 4: $165-178$.

8. Akin, D.T., J.M. Kinkade, Jr., and R.T. Parmley. 1987. Biochemical and ultrastructural effects of monensin on the processing, intracellular transport, and packaging of myeloperoxidase into low and high density compartments of human leukemia (HL-60) cells. Arch. Biochem. Biophys. 257:451-463.

9. Nauseef, W.M., S.J. McCormick, and R.A. Clark. 1995. Calreticulin functions as a molecular chaperone in the biosynthesis of myeloperoxidase. J. Biol. Chem. 270:4741-4747.

10. Nauseef, W.M., S.J. McCormick, and M. Goedken. 1998. Coordinated participation of calreticulin and calnexin in the biosynthesis of myeloperoxidase. J. Biol. Chem. 273:7101-7111.

11. Nauseef, W.M., M. Cogley, and S. McCormick. 1996. Effect of the R569W missense mutation on the biosynthesis of myeloperoxidase. J. Biol. Chem. 271:9546-9549.

12. Nauseef, W.M., S. McCormick, and H. Yi. 1992. Roles of heme insertion and the mannose-6-phosphate receptor in processing of the human myeloid lysomal enzyme, myeloperoxidase. Blood. 80:2622-2633.

13. Lehrer, R.I., and M.J. Cline. 1969. Leukocyte myeloperoxidase defi- 
ciency and disseminated candidiasis: the role of myeloperoxidase in resistance to Candida infection. J. Clin. Invest. 48:1478-1488.

14. Tobler, A.M., E. Selsted, C.W. Miller, K.R. Johnson, M.J. Novotny, G. Rovera, and H.P. Koeffler. 1989. Evidence for a pretranslational defect in hereditary and acquired myeloperoxidase deficiency. Blood. 73:1980-1986.

15. Boyum, A. 1968. Isolation of mononuclear cells and granulocytes from human blood. J. Clin. Lab. Invest. 21:77-89.

16. Nauseef, W.M., S. Brigham, and M. Cogley. 1994. Hereditary myeloperoxidase deficiency due to a missense mutation of arginine 569 to tryptophan. $J$. Biol. Chem. 269:1212-1216.

17. Borregaard, N., J.M. Heiple, E.R. Simons, and R.A. Clark. 1983. Subcellular localization of the b-cytochrome component of the human neutrophil microbicidal oxidase: translocation during activation. J. Cell. Biol. 97:52-61.

18. Sottocasa, G.L., B. Kuylenstierna, L. Ernster, and A. Bergstrand. 1967. An electron transport system associated with the outer membrane of liver mitochondria. J. Cell Biol. 32:415-438.

19. Nauseef, W.M., and R.A. Clark. 1986. Separation and analysis of subcellular organelles in a human promyelocytic leukemia cell line, HL-60: application to the study of myeloid lysosomal enzyme synthesis and processing. Blood. 68:442-449.

20. Zeng, J., and R.E. Fenna. 1992. X-ray crystal structure of canine myeloperoxidase at 3 A resolution. J. Mol. Biol. 226:185-207.

21. Arnljots, K., and I. Olsson. 1987. Myeloperoxidase precursors incorporate heme. J. Biol. Chem. 262:10430-10434.

22. Hur, S., H. Toda, and M. Yamada. 1989. Isolation and characterization of an unprocessed extracellular myeloperoxidase in HL-60 cell cultures. J. Biol. Chem. 264:8542-8548.

23. Tucker, K.A., M.B. Lilly, L.J. Heck, and T.A. Rado. 1987. Characterization of a new human diploid myeloid leukemia cell line (PLB-985) with granulocytic and monocytic differentiating capacity. Blood. 70:372-378.

24. Lozzio, B.B., and C.B. Lozzio. 1979. Properties and usefulness of the original K-562 human myelogenous leukemia cell line. Leukemia Res. 3:363-370.

25. Jensen, T.J., M.A. Loo, S. Pind, D.B. Williams, A.L. Goldberg, and J.R.
Riordan. 1995. Multiple proteolytic systems, including the proteasome, contribute to CFTR processing. Cell. 83:129-135.

26. Castaneda, V.L., R.T. Parmley, I.B. Pinnix, S.G. Raju, G.S. Guzman, and J.M. Kinkade, Jr. 1992. Ultrastructural, immunochemical, and cytochemical study of myeloperoxidase in myeloid leukemia HL60 cells following treatmen with succinylacetone, an inhibitor of heme biosynthesis. Exp. Hematol. 20:916-924.

27. Pinnix, I.B., G.S. Guzman, H.L. Bonkovsky, S.R. Zaki, and J.M. Kinkade, Jr. 1994. The post-translational processing of myeloperoxidase is regulated by the availability of heme. Arch. Biochem. Biophys. 312:447-458.

28. Ward, C.L., S. Omura, and R.R. Kopito. 1995. Degradation of CFTR by the ubiquitin-proteasome pathway. Cell. 83:121-127.

29. Kopito, R.R. 1997. ER quality control: the cytoplasmic connection. Cell. 88:427-430.

30. Werner, E.D., J.L. Brodsky, and A.A. McCraken. 1996. Proteasomedependent endoplasmic reticulum-associated protein degradation: an unconventional route to a familiar fate. Proc. Natl. Acad. Sci. USA. 93:13797-13801.

31. Hiller, M.M., A. Finger, M. Schweiger, and D.H. Wolf. 1996. ER degradation of a misfolded luminal protein by the cytosolic ubiquitin-proteasome pathway. Science. 273:1725-1728.

32. Ou, W., P.H. Cameron, D.Y. Thomas, and J.J.M. Bergeron. 1993. Association of folding intermediates of glycoproteins with calnexin during protein maturation. Nature. 364:771-776.

33. Cross, A.R., J.T. Curnutte, J. Rae, and P.G. Heyworth. 1996. Hematologically important mutations: X-linked chronic granulomatous disease. Blood Cells Mol. Dis. 22:90-95.

34. Thrasher, A.J., N.H. Keep, F. Wientjes, and A.W. Segal. 1994. Chronic granulomatous disease. Biochim. Biophys. Acta. 1227:1-24.

35. Wright, A.H., W.A. Douglass, G.M. Taylor, Y.L. Lau, D. Higgins, K.A. Davies, and S.K.A. Law. 1995. Molecular characterization of leukocyte adhesion deficiency in six patients. Eur. J. Biochem. 25:717-722.

36. Nauseef, W.M. 1986. Myeloperoxidase biosynthesis by a human promyelocytic leukemia cell line: insight into myeloperoxidase deficiency. Blood. 67 : 865-872. 